\title{
Immunoglobulin Heavy Constant Gamma 4 Measurement
}

National Cancer Institute

\section{Source}

National Cancer Institute. Immunoglobulin Heavy Constant Gamma 4 Measurement. NCI Thesaurus. Code C154738.

The determination of the amount of immunoglobulin heavy constant gamma 4 present in a sample. 